\title{
'Performing Surfaces'
}

\section{Designing Research-creation for Agentive Embodiment}

\author{
NiCOLE DE BRABANDERE \\ LINZ UNIVERSITY OF THE ARTS \\ ZURICH UNIVERSITY OF THE ARTS
}

This article starts from the premise that critically engaging the movements, sensations, qualities, techniques and affects of everyday experience will give insight into designing research-creation strategies for agentive embodiment. Researchcreation proposes the possibility of becoming newly sensitive to affective and sensorial influences via material and medial negotiation which, in turn, can modulate habits of attention and the way we tend to everyday experience. How, then, can research-creation processes activate agency in habit, which is entwined in personal histories of emotion and perception, so that it can become a creative force in both personal and collective contexts?

To explore this issue, I have composed a series of thematic gatherings that integrate theoretical, reflective and artistic examples. I first consider everyday, material interaction as a process of emergent embodiment. I then explore how agency is constituted in embodied movement and sensation more specifically by extending the discussion of embodied agency to instances wherein felt sensations

Cultural Studies Review 2014. @ 2014 Nicole De Brabandere. This is an Open Access article distributed under the terms of the Creative Commons Attribution 4.0 Unported (CC BY 4.0) License (https://creativecommons.org/licenses/by/4.0/), allowing third parties to copy and redistribute the material in any medium or format and to remix, transform, and build upon the material for any purpose, even commercially, provided the original work is properly cited and states its license.

Citation: Cultural Studies Review (CSR) 2014, 20, 3368, http://dx.doi.org/10.5130/csr.v20i2.3368 
are intensified and generated via procedures within which to formalise it. I introduce 'tactile drawing', an exercise I designed to demonstrate how refocusing existing, linear perception parameters can generate emergent sensitivity in the movement and sensation of tactile experience. I then discuss embodied agency via the mediated, affective and perceptive intensification of research-creation processes. Finally, I consider Sara Ahmed's proposition that clumsiness can destabilise emotionally charged habits of boundary and social distinction. I suggest that engaging social frictions and tensions with clumsy non-attunement in processes of research-creation can generate emergent sensitivity across affectively charged social boundaries, manners and habits.

My aim for this discussion is to develop both affective and critical resonances between theory, reflection and artistic expression, so that it becomes a context with which to develop research-creation from the often non-conscious continuities of habit. The central theme of agency in habit is not examined for the discreet purpose of explaining it. Instead, the notion of embodied agency is a focalisation with which I engage the experience of habit, so that embodying processes can be designed that have the potential to intensify and modulate everyday experience. My theoretical contribution thus lies in composing a dynamic milieu for emergent thought and reflection, to bring theory closer to the development of agentive, inhabitable and socially pertinent embodiment processes.

\section{-MATERIAL SCRIPTS}

It is important to consider how everyday, embodied habits are developed via dynamic scripts or tendencies within material, relational milieux. For Elaine Scarry, the process of embodying an object is two-fold. The body is anatomically augmented with specific prosthetic objects that prolong, transform and facilitate specific tasks, and project the perceptive limits of the body outwards. Correspondingly, these same objects are internalised, objectifying the body. ${ }^{1}$ Scarry specifically elaborates on the perceptive relation of the internal and external body in instances when pain is relieved by extending sentience into ergonomic objects like furniture. When one relieves their pain by sitting on a chair, the body is objectified-it takes on 'that blissful immunity of inert, inanimate objecthood'.2 Meanwhile, the chair assumes the vulnerability and sentient consciousness of the relieved sufferer. Embodiment itself 
is thus a loose and porous dynamic of intensive surfacing with surrounding materiality: 'a body-is itself at its origins a profound registration of the fact that physical sentience has, after first projecting itself outward, then absorbed back into its own interior content the externalised objectifications of itself ' ${ }^{3}$

In reference to Heidegger, Robin Bernstein distinguishes objects from things to better grasp the physical and psychological transformation that occurs when bodies move with things in processes of embodiment. Bernstein suggests that a distinction can be made between objects and things based on the level of ease and fluidity of their interrelationship with the body in use. Objects become things when 'thing and person are unmoored from fixed positions of difference and twirl in sudden mutual orbit, each subject to the other's gravity ... an object becomes a thing when it invites a person to dance'.4 Our relationships with things are thus not closed, automatic circuits of movement, but dynamic bodying processes in flux.

In fact, the more invested we are in embodying a specific relational dynamic with an object, the more fluid our relationship with it becomes. For example, when cutting with a knife, the agility of grip or the pressure, span and rhythm of slicing are modulated with even greater subtlety and dynamism as our skill level increases. Embodied object scripts thus invite 'an elastic resilience with a necessary openness to resistance, interpretation, and improvisation'. ${ }^{5}$ The dynamics of attention in the movement of slicing is not strictly a concern for either body or object, for cutting or getting cut, but a negotiation of mutual co-constitution. ${ }^{6}$

William James further suggests that our understanding of materiality is purely relational. For James, our experience with objects, the way their material quality, weight, texture, temperature or resistance variably weighs on our attention in practice is all that we can know of them: 'but denoting definitely felt transitions, lies all that the knowing of a percept by an idea can possibly contain or signify'. ${ }^{7}$ What we perceive is then always mediated in shifting relations of desire and circumstance. David Ellison confirms that 'we notice what we need or desire to know and negate the perceptibility of the which fails to meet these criteria'. 8 This relational emphasis does not undermine the significance of materiality but locates materiality as the precondition of sensation, which itself is felt and articulated in an active dynamic with the sensory materiality of the body. 
We can feel the dynamic attention of embodied materiality in action in Erin Manning's 'Dance of Attention'. This exercise specifically activates how we consciously inhabit material spaces that have been embodied over time. Participants lie flat on their backs and are given a series of verbal cues to help them mentally recreate the surrounding space. However, rather than assume that our memory of material interaction can be a matter of recalling a static and singular position or quality, we see that embodied attention is a force that actively generates material and spatial memory. Manning describes this process as a 'body-event of space timing'. ${ }^{9}$ When we dance with 'things', we are dancing with embodied material experiences that are composed from and expressed in dynamic attention.

I have experienced firsthand the dynamism of emergent sensorial sensitivity with particular intensity during the process of learning to form plastic clay into a vessel on a potter's wheel. This process requires gradually embodying a subtle and tactile responsiveness to the weight and consistency of spinning clay. The process is unique in the complexity, sensitivity and immediacy of sensory feedback.

When I was first learning to throw pottery, the multitude of undifferentiated sensations bombarded my attention and I was unsure of their causal effects on the clay-forming process. For example, the effects of the pressure of touch on the clay were very different depending on its humidity and corresponding consistency. The speed of the turning wheel also had a dramatic effect on my ability to negotiate and feel the effects of the centrifugal force as it exerted the weight of the clay and against my hands. For me as a beginner, the pressure dynamics involved in this process felt extremely subtle and at times obscure. The degree of sensitivity required to press the clay into the form required that I embody a certain amount of habitual automatism. Only once was I able to negotiate the weight and pressure of the clay with a practised, accumulated muscle reflex that could successfully form the clay into a vessel form. I noticed that subsequent, more expertly formed vessels became the expression of this specific embodiment. The complexity and very specialised character of throwing made me acutely aware of the process of developing perceptive and muscular sensitivity to it-learning to throw became a process of designing my own embodiment. 
This example shows that learning to throw pottery is a process of learning to design vessel forms as much as it is a process of designing embodiment. This notion is inspiring in that it reveals how to explicitly develop embodied agency by inhabiting expressive techniques. How, then, can processes of designing agentive embodiment be developed in everyday and social contexts? To answer this question, it is useful to specifically examine agency in embodied movement.

\section{-AgenCY IN MOVEMENT}

Movement is expressed in the emergent dynamics of embodied perception in space. Bergson affirms that even micro-perceptive movements like the shift of a glance or a muscle contraction are 'neither the cause nor the result of its relation to phenomenon; they are part of it, they express it in terms of space'.10 After Suzanne Langer, Massumi elaborates on the example of visual movement in a leafy motif to explain the embodied, spatial quality of movement expression. The cursive fluidity of the form visually motivates attention: 'Every perception comes with its own "vitality affect"... that's why we see movement in a motif. The form "naturally" poises the body for a certain set of potentials'.11 This vitality effect is a sensing of aliveness that is felt self-referentially 'in the immediacy of its occurrence, as it is feltthinking-feeling'.12 This 'thinking-feeling' is how we feel the activity and agency of our participation in the process of perception, whether we are aware of all the embodied qualities that constitute perception at a given moment or not.

Massumi clarifies the conceptual importance of understanding movement as embodied, emergent expression and not merely as the displacement of static bodies and positions. Positions can be easily mapped or plotted on a grid, accounting for multiplicity and displacement but not qualitative transformation, precluding emergent thought in motion. In motion, the potential of the body unfolds in variation; it 'does not coincide with itself. It coincides with its own transition: its own variation'.13

But, if even the slightest movements necessary for vision and other basic motor skills express subjective embodiment, the question of how we can actively catalyse movement as a multiple and dynamic method of developing techniques for agentive embodiment remains. Massumi aptly states 'the movement is always there in any case. So you have to make distinctions between kinds of movement, kinds of 
experiential dynamics, and then ask what difference they make.'14 We can start to engage the impact of perception on experiences of agency by connecting perceptive movements to the impulses that shape everyday movements like walking or jumping.

Manning insists that identifying specific movements resides in a retrospective awareness of it. However, this after-the-fact movement consciousness does not imply that we have no control over our movements. Instead, we actively preaccelerate movement via the embodied coordination of movements that have been travelled before but that resist precisely predetermined trajectories:

Movement always begins with a certain degree of open improvisation mixed with a certain degree of habit. Every step we take when we walk is a re-playing of a habit ... These habits hold our walk to a practised repetition: a choreography of sorts. Yet each of these habits takes its shape from a pre-acceleration that proposes openings toward different shades of movement. 15

The potential for shifting experience in movement, then, is a matter of creating a context wherein divergent movement trajectories can emerge and develop from within the practised automatism of habit. Manning explores this potential by adapting the tango so that dance movements are systemically delayed and improvised. Dancing partners activate an affective exchange between them through the very materiality of their bodies in movement. The object of the dance is not a stable image, position or discreetly defined trajectory but the exchange of closeness in the immediacy of felt breath, boundary and anticipation or 'a listening to what might be considered the very ethics-in-deconstruction of humanity'. ${ }^{16}$ For Manning, this is an ethical encounter with the other in which movement is a central force for rethinking dominant subject categorisations.

The choreographies of Meg Stuart, including Forgeries, Love and Other Matters (2004), All Together Now (2008) and The Fault Lines (2010), also generate a performative context that transforms everyday impulses to movement and embodiment. ${ }^{17}$ The minutia of a gesture that is as slight as shaking one's head or extending a hand is distilled into a brief and potent physical manifestation. The figural body is abstracted and deconstructed from everyday familiarity in the fastpaced intensity of fragmented or incomplete repetition of gestures. Unlike 
Manning's tango, which stretches movement out to make room for new experiences within practised tendencies, Stuart's bodies are condensed and accelerated to the limit of physical capacity. In Stuart's extreme movement sequences, embodied poses are elasticised, contaminated and hybridised in emergent and fluid spatial expression. ${ }^{18}$ This is a severe redistribution of embodied movement and expresses the intensity of inhabiting the threshold of an elastic body.

Embodied movement is clearly one parameter with which to instigate strategies for modulating habitual trajectories. But movement is not the only parameter with which to account for felt experience. The affective and sensorial textures of experience play a crucial role in our ability to modulate attention and thus our embodied agency with the materiality of the everyday.

\section{-AgenCy IN SENSATION}

Like movement, discreet sensations in habit are entangled in the immediacy of experience. But, unlike movement, which is always only known by our retrospective awareness of it, sensation gives us access to immediately palpable, material awareness. What's more, our experience of sensation enables us to shift movement tendencies in process. For Bergson, this ability to feel in movement is the foundation of sensory agency: pain and pleasure resist habitual automatism as a form of 'nascent freedom ... [sensations foresee] future automatic movements in the very midst of the sensation'.19

Tim Bayne goes so far as to suggest that knowledge and agency are embedded and developed through sensory perception. For Bayne, agentive experiences are best thought of as perceptual experiences, which is the mode in and through which we are self-aware and the condition for our consciousness of agency. Perceptual organs cannot then be conceived as passive perceptions, but are organs that generate awareness as part of their phenomenology. ${ }^{20}$ Sensory information thus constitutes experience in dynamic and elastic interrelationships that are not always conscious but nonetheless inform our actions, agency and subjectivity.

Sensory agency is perhaps experienced most directly with intensely felt sensations. For example, when skin comes into contact with a hot surface or a toe hits a hard corner in mid step, the feeling of intense pain provokes an immediate, often involuntary, physical response. However, our physical response to less intense 
sensations is also mediated in quasi-automatic movements that activate perceptive sensitivity. As Dewey explains: 'Habit means special sensitiveness or accessibility to certain classes of stimuli, predilections and aversions, rather than bare recurrence of specific acts.'21 Embodied sensitivity to sensory information is thus developed and modulated over the long-term investment in refining patterns and tendencies of physical and reflexive co-ordination: 'To single out a definitive sensory element in any field is evidence of training.'22 Agentive embodiment is then the expression of an accumulation of trained body-creation or culturally, physically and affectively mediated sensitivities and aversions, which are constituted as subjective tendencies rather than fully conscious, discreetly defined acts.

Deleuze emphasises the role of the plastic, perceptive capacity of the body in sensory agency. He explains that sensory experience is synthesised by the living, embodied present, 'the thousands of habits that compose us, our contradictions, thoughts, pretensions, presumptions, satisfactions, fatigues and variable presentsform the base domain of passive synthesis'.23 Since habitual reflexes actively shape perception, this means that 'we must attribute a contemplative spirit to the heart, muscles, nerves and cells whose role is to contract habit'.24 Therefore, embodied agency is delocalised from a contained body or object. Instead, agency is an activation of the flux between the body and the material environment, in a dynamic negotiation of inhabited tendencies to movement and affective sensitivity with the immediate.

As we have seen in the earlier example of learning to throw pottery, embodied, sensory agency does not correlate with being fully conscious of all the physical details and perceptions that go into a particular movement. Ellison points to the instances when we first notice a clearly articulated background noise that was always there to begin with as awareness of our selective consciousness. The routine indifference to these kinds of aural details is an expression of the dynamism of conscious and non-conscious sensation: it is both the pre-condition for focusing on an isolated sensory dynamic (or of honing techniques that require particular sensory refinement) and the 'necessary precondition of its return to perceptibility'. ${ }^{25}$ Habit, then, is never only a matter of developing a relative consistency in action, but is constituted in a relational milieu of competing, sensory stimuli. This explains the feeling of stability when attention is streamlined during the practice of a given skill. 
This felt stability is immediately experienced as improved balance if one imagines that a string is attached to the head and connected to the ceiling, holding them up.

To complicate the issue further, the felt sensations, affections and reflections that make up experience are not discreetly defined entities but are condensed in shared reflexive tendencies that become indistinguishable and interchangeable. Even the most mundane experience of sensory perception can incite a deeply emotional response. Bergson outlines the difficulty of differentiating what we perceive as magnitude and sensory extensities that pertain equally to psychic states, muscular effort and pain:

We are thus led to define the intensity of a superficial effort in the same way as that of a deep-seated psychic feeling ... a feeling which, retaining the same name, grows without changing its nature ... Sometimes these superficial elements are co-ordinated by a purely speculative idea, sometimes by an idea of a practical order. ${ }^{26}$

Bergson's observations about the interchangeability of psychic and sensorial responsiveness are clinically affirmed. Ronald Melzack and Patrick Wall's 1965 essay, 'Gate Control Theory of Pain', which continues to underscore contemporary pain research, shows that touch, pressure and vibration signals are shared on the same spinal cord fibres and often interact. The shared neuro-signalling involved in sensory perception can be experienced first hand by rubbing a bumped knee or elbow to generate the sense of vibration, which prevents painful sensory transmission to the brain. What is especially fascinating is that the interconnected biological formation of spinal and neural transmission is not static or hard-wired but alive and continually changing. ${ }^{27}$ Therefore, the physical links or associations that we make between sensorial registers in practice actively and physically form our subjective, perceptive disposition.

\section{-AgenCY IN ATTENTION}

Examples from empirical research show how measurement apparatus activate and intensify sensation according to the constraints of their measurement parameters. Let us now consider a few examples of this process, which will in turn help to conceptualise possible new procedures for developing ways of affectively tending to the everyday environment. ${ }^{28}$ 
Massumi describes an experiment by David Katz that measures the impact of emotion on perception within the specific parameters of a test scenario. In the experiment, participants were asked to remember the colour of an object that carries emotional or personal importance to them. Participants consistently remembered a 'striking particularity' of the colour, rather than the colour itself, which resulted in a colour memory that was excessive in saturation and intensity. ${ }^{29}$ In the Katz test scenario, the affective parameters of the experiment focalise memory so that the perception of colour is intensified. Excessive saturation emerges in the focalised co-constitution or conflation of emotional and perceptive registers.

A recent experiment published by the International Association for the Study of Pain (IASP) similarly creates an excess of pain intensity by combining the experience of thermally induced pain with affect as described by facial expression. The study concludes that patients felt substantially more pain when simultaneously viewing more intense illustrations of pain. ${ }^{30}$ Like the Katz experiment, this test scenario demonstrates that sensation is significantly modulated by the agentive dynamic in the measurement apparatus itself.

From these examples we can see that empirical measurement processes participate in the production of sensation. When we contrast empirical methods of pain self-assessment with more open pain description systems, the complexity of this process comes further to light. The 'Schmidt Pain Index' is an index that Justin 0. Schmidt developed to rank the sensations of the sting of seventy-eight different wasp species. Rather than reduce sensations to intensity alone, Schmidt explores textual association, metaphor and comparison to describe the subjective experience of intensity, as well as physical and emotional effects in sensation. For example, Paraponera clavata stings induce 'immediate, excruciating pain and numbness to pencil-point pressure, as well as trembling in the form of a totally uncontrollable urge to shake the affected part'.31 The Yellow Jacket sting is described using more poetic associations. It is 'hot and smoky, almost irreverent. Imagine W.C. Fields extinguishing a cigar on your tongue'. ${ }^{2}$ The attempt to describe sensation without the constraint of a linear, intensive constraint, reveals the potential for generating complex, expressive outcomes from perceptive focalisation. Sensation is activated and transformed in the very parameters used to measure, articulate and reflect upon it. 
-TACTILE DRAWING

In keeping with the notion that perception is generated via the parameters of its focalisation and articulation, I developed tactile drawing, a form of drawing that introduces emergent qualities of sensory experience into standard, linear pain selfassessment schemes. Tactile drawing adapts the commonly used universal pain selfassessment scale so that felt variations in tactile articulation when moving over a textured surface with the fingertip are assessed. The colours of the pain scale are matched with coloured pencil crayons and correspond to an intensive scale of felt articulation. Participants then directly draw the felt dynamism of tactile experience as a visual topography. The reductive parameters of standard pain self-assessment are inverted so they expand the criteria for perceptive attention and generate emergent sensation.

I presented tactile drawing to four groups of participants. I developed a series of constraints called points of focus to help participants who struggled with the exercise to engage with it more confidently. These consist of a series of attention parameters and technical considerations that help participants focalise their

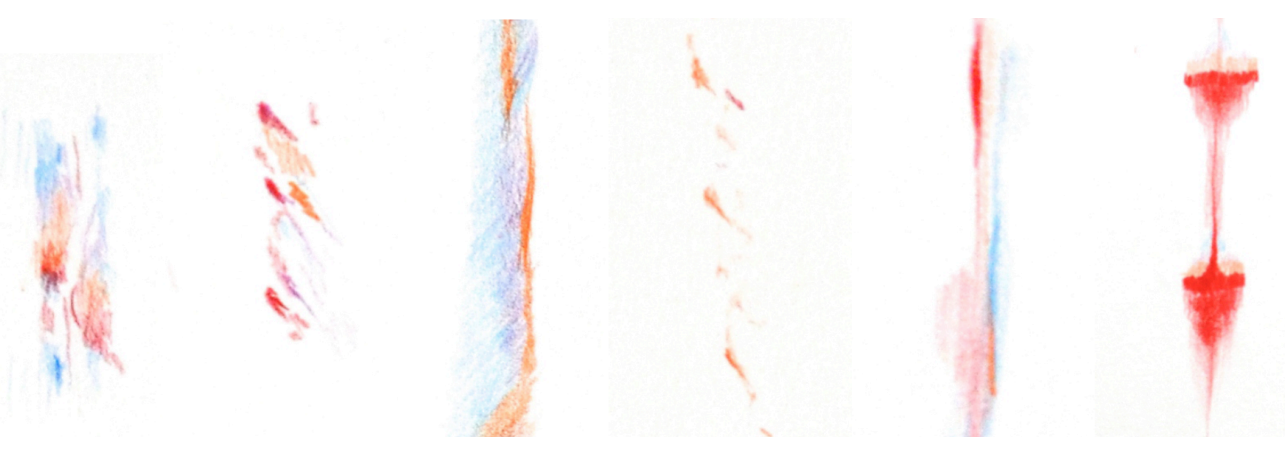

Sensory articulation scale:

Slight sensation

Vaguely articulated sensation

Clearly articulated sensation

Figure 1: Drawings made by participants of the 'Tactile Drawing' workshop. The various examples demonstrate the participants' attempts to negotiate the visual articulation of sensation, as it is felt in continuous movement as compared to in periodic instances (notice the drawn 'pulses' of sensation, far right), as well as the tactile variation that is simultaneously felt on different areas of the fingertip. 
experience within the open shifting milieu of tactile perception. These include: a) continuity/periodicity or accounting for the way that edges or small details are felt differently when the finger tip approaches them as compared to when it moves along and past them; b) fingertip area or the way sensations are articulated differently on different areas of the fingertip; c) hybrid distortion or negotiating the way surfaces are perceived as a quality of embodied fingertip sensation and as compared to the specific materiality of a surface; d) increasing or decreasing the pressure of a finger tip when moving against a surface to modulate the form of sensory detail and intensity; e) increasing or decreasing the speed of a finger tip moving against a surface to modulate the form of sensory detail and intensity; f) pulling/tautness of the skin or considering how the sensation of pulling the skin modulates sensory emphasis or articulation; g) vibration/tickle or notating the sensation of a tickle or vibration that is felt up the length of the finger; $h$ ) drawing technique or how the specificity of line and shading can create an appropriate scale to articulate how sensations are felt.

Within these notational parameters remain challenges that complicate some participants' ability to directly notate their tactile experience. For example, participants occasionally become involved in notating the time of sensation in discreet movement periods rather than a continuous experience of sensation in realtime. In these instances participants often describe the sequential rhythms that correspond to the time that it takes for the span of the fingertip to traverse an equal length of surface. ${ }^{33}$

A second important consideration in tactile drawing is the choreography of touch or the touching techniques required to feel complex surface textures. To feel textured details the finger must delicately move with them, maintaining consistent contact without excessive pressure or speed. For example, the fingertip must lightly move over soft towel fibres so they do not flatten into a homogenous texture under the weight of the finger when it moves over them. It is also important to avoid fingertip desensitisation. If the fingertip moves over a surface with excessive speed and pressure, the finger vibrates and the nerve endings that register pressure are desensitised. This makes detailed and sensitive notations of tactile articulation impossible. 
Appropriate scaling is also important for becoming aware of emergent sensory details in the tactile experience. I have found that traditional drawing techniques that start with a very light grade pencil and which progressively include heavier grades of pencil to articulate darker and more specific lines is a very useful strategy. I encourage participants to begin the notation process by mapping out a general feeling of slight sensation using the light blue pencil and then gradually introduce the other colours to relationally define more clearly articulated sensations. This creates a relational field or reference system in which finely scaled sensations can emerge in relation to more obviously felt sensations, greatly increasing the detail of tactile articulation.

When performed successfully, tactile drawing becomes an exercise in producing differentiations that recover tactile quality from the reductive parameter of the intensive self-assessment scale. This process gives the participant access to a large range of sensorial qualities that were previously unnoticed since there was no attentive frame or parameter within which to experience them. This is seen perhaps most strikingly in the variety of ways the feeling of a textured surface is articulated and how tactile sensation often appears to shift the participants' attention parameters over the course of doing the exercise. This is because in the search to feel and articulate the complexity of the tactile experience, different points of focus are sequentially employed to resensitise attention. ${ }^{34}$

Although the emergent sensation of tactility in tactile drawing is of a relatively small scale, it speaks to the much more urgent issue of how habits of attention sensitise and desensitise the rich complexity of perceptive experience in everyday life. Given the interconnected character of emotion and sensation in felt experience, we cannot underestimate how deeply habits of perception inform even the most natural-seeming social and emotional tendencies. What's more, in tactile drawing we see that the way we understand the boundary of our physical extremities is constituted in the plastic dynamism of perceptive experience. Tactile drawing thus proposes a mode of figurative representation that does not reduce the body to an impermeable, visual outline, but expresses a plastic, agentive experience of body surfacing in touch. The felt emergence of sensation that is experienced via the tactile drawing exercise brings us to consider how the sensorial, material and medial dynamics of research-creation become a milieu of emergent embodiment. 
—DESIGNING TECHNIQUES OF AGENTIVE EMBODIMENT IN RESEARCH-CREATION

Tactile drawing reveals that moving, sensing and measuring are always situated within an emergent, relational ecology and guided in dynamics of attention. Like the formalism of the apparatus, research-creation processes specifically pressurise attention and sensitivity within a given media and material milieu. But, the complexity in the way that we condense and perceive sensory information suggests that we can only develop sensory agency in practice, in the felt experience of doing.

Thomas Lamarre confirms that sensory agency in experience can only be understood during the immediate process of its actualisation. For Lamarre, the transfer of sentience manifested as physical consciousness between the body and material surroundings during the performance of a specific task is exemplified most explicitly at the threshold of tactility. Lamarre uses calligraphy to describe a becoming in sensory agency that recreates the limitations of the body: 'The discipline of calligraphy ... constitutes a radical mutilation and mutation of the body. In particular, there is an amputation of the hand in favor of a new prosthetic hand/brush that transforms modes of touching. ${ }^{35}$ The condition of movement amplifies the effect of inverting the interior and exterior body at the specific location where the hand holds the brush: the ink that metaphorically bleeds from the brush loosens the sensory body from its contained physical form.

In the example of calligraphy ink, paper and brush play an important role in specifically sensitising habitual tendencies to movement. The limitations of the body are reformed in the relational negotiation of materiality-the spring of the brush, the viscosity of the ink, the texture, weight and porosity of the paper and brush bristles, body posture, the embodied skill or technique that is characteristic of a particular style or technique of brushwork or way of holding the brush. Once again, the issue of process does not simply amount to the steps involved in reshaping the materiality of everyday objects. Instead, the particular affordances of a given material or medial technique initiate movements towards an inhabitable sensory sensitivity that stretch beyond existing limits of the subjective self. Like in the doing of calligraphy, this process is felt with particular intensity in the process of learning to throw pottery. 
During my experience learning to throw pottery, I participated in a process of identifying, curtailing and transforming everyday embodied habits by negotiating specific formalism, technology and materiality.

While throwing a cup, the walls of the soft clay vessel can only be felt from a single point on the tip of the fingers or knuckles. The clay forms into shape as it is forced through the narrow passage of two nearly touching fingertips. The cup is no longer an object of material stability acquired over time from the embodied memory of holding countless cups in the past. By forming a cup from plastic clay, the stability of my past experience holding solid cups is transformed into an emergent process that is in flux with the body. All previous experience with cups must temporarily be ignored or deliberately unformed in embodied consciousness to successfully articulate a cup in the plastic malleability of the throwing process. The affective disparity in the process of throwing and using a cup is felt most acutely when the rim of a cup is no longer felt as a stable point that supports the lips while drinking, but as a dynamic articulation that is felt in a flux of movement, time and tactility with the spinning clay.

Although learning to throw pottery is a gradual process of self-reflexively embodying technique, which potentiates the further creative design of vessel forms, the training involved in this process is not a technical means to a creative end. Instead, habits of technique and aesthetic sensitivity are simultaneously developed, refined and embodied via the training process. Despite this confluence of technical and aesthetic embodiment, it remains important to conceptualise the embodied emergence that occurs in the doing of research-creation as compared to the doing of technical skill.

After Deleuze, Andrew Murphy distinguishes the probabilistic yet shifting continuities in habit from the more complex and discontinuous synaptic relationships that are involved in creative thought patterns. Murphy explains that creative tracings 'face up to discontinuities ... making something new of them (entirely new syntheses)- "in which there is a gap that must be jumped"'.36 Although Murphy separates habitual continuity from creative 'jumps', he also affirms that both 'habit and creative discontinuities will always be found in 
combination' and will contribute to 'the complexity of the probabilistic nature of synaptic activity'. ${ }^{37}$

To understand what is specific to embodied creative processes as compared to embodiment processes in general it is important to consider the implications of 'making something new'. Newness as an attribute of creative expression is more complex than it seems since the process of learning a technical skill equally potentiates embodied expression and new forms of sensory distribution, sensitivity and affect. However, technical expertise is also a process of streamlining and reducing emergent sensation within the parameters of an existing format or system-technical training is a means to achieving a pre-specified end. ${ }^{38}$ In technical training we often become desensitised to the potential for creative emergence.

Meanwhile, the practice of poising oneself to creatively respond to or 'face up' to the discontinuities of experience, or the moments of sensory flux that are felt by tending to the immediate, constitutes a systemic openness to experience that is beyond habit or training. The example of tactile drawing shows us that this 'facing up' is less a posture towards occupying a 'gap' or a 'jump' that is completely severed from existing habitual tendencies, but a newly sensitive engagement that is only possible from within habitual continuities. Sensory agency in creative expression is then a process of developing affective sensitivities from within the dynamic flux experience, which is always constituted in a milieu of emergent sensorial motivations. Bergson affirms the intensive, expressive potential of sensation:

If the art which gives only sensations is an inferior art, the reason is that analysis often fails to discover in a sensation anything beyond the sensation itself. But the greater number of emotions are instincts with a thousand sensations, feelings or ideas which pervade them. ${ }^{39}$

In creative media and material contexts, embodied, perceptive impressions of the world are quickly and easily reconfigured in infinite permutations, with the effect of pressuring attention in new trajectories. This process can take the form of wrestling with a partially formed vessel or sculpture, transforming an image of the world within the spatial and formal parameters of editing software or attempting to visually represent the details of a scene with a thick and chalky utensil. These material or medial transformations emerge through the plasticity of affective 
embodiment itself as they reconfigure, absorb and condense affective projections and internalisations.

Giaco Schiesser aptly posits the term Eigensinn to describe the production of stubbornness that sustains the affective negotiation of media, materials and individuals during creative processes. He considers the confrontation of resilience between these elements in research-creation to be the central motivating force:

The Eigensinn of individuals is best described by the consciousunconscious, sometimes bizarre and often contradictory will to do that which they want to do, under whatever conditions, by their selfdetermined actions ... [the Eigensinn of the medium is described as the] undiscovered possibilities and obstinacies ... [of the] materiality, structure, and technology specific to the chosen medium. ${ }^{40}$

In research-creation the technical dynamics of the media or material milieu become the intensive force for negotiating and modulating felt embodiment. The parameters of embodiment or the limits of sensation become the very subject of expression. How, then, can the procedural openness of material or media techniques in research-creation transform collective willfulness towards sensory agency that is felt as a participatory, collective agency? Or, how can emergent sensation in media and material processes be applied to social contexts towards developing a more flexible and sensitive social milieu wherein emotionally and affectively charged boundaries and manners become a cite of creative negotiation rather than disciplinary enforcement?

\section{-Clumsy Agency}

Sara Ahmed considers unexamined affective or emotional compulsions to have important consequences for how people behave socially and politically: 'attention to emotions allows us to address the question of how subjects become invested in particular structures such that their demise is felt as a kind of living death'. ${ }^{41}$ For example, issues like nationalism and naturalisation often carry an affective charge of social belonging or exclusion. Ahmed considers the emotions that compel people to affirm issues like national borders to be a type of social stickiness: 'To get stuck to something sticky is also to become sticky ... stickiness then is about what objects do 
to other objects-it involves a transference of affect-but it is a relation of doing in which there is not a distinction between passive or active.'42

'Stickiness' is a compelling notion with which to critically engage the issue of how collectivities actively invest in distinguishing borders and people, not as a reasoned consideration of the issues at play, but as a charged emotional response. Like habitual compulsions, sticky issues or concerns are embedded in complex processes of affective embodiment. In habit we often get 'stuck' to the path of least resistance wherein emotional and perceptive tendencies enable us to avoid confronting the felt abrasiveness of un-sticking. This leaves us with the problem of developing techniques that can transform undifferentiated and unexamined sensations and experiences into active processes of sticking, unsticking and resticking. Ahmed proposes clumsiness as one possible technique that can undermine the continuity of such emotional lines of social and political affiliation.

For Ahmed, clumsiness is an experience of non-attunement, which disrupts social willing, which is a willing in time with others towards the aim of synchronicity. ${ }^{43}$ Thinking of clumsiness in terms of non-attunement or social dissynchrony implies that clumsiness disrupts the continuity of social anticipation by uncoordinating perceptive, temporal or scalar frequencies of action. To better understand how clumsiness might become an operative force in transforming social manners, it is first useful to examine the affective, homogenising glue of social synchronicity.

Bergson specifies that the affective quality of synchronicity be expressed by grace. Grace has a way of aligning social sympathies in streamlined continuity. As we anticipate the temporal flow in the graceful motion of another, 'we believe that we control them'.44 This feeling of control over another has the corollary effect of evoking sympathy for the self. When we witness grace we anticipate a mobile sympathy, which is a 'virtual and even nascent sympathy towards ourselves'. ${ }^{45}$ To visually follow the graceful movements of another means to sympathetically anticipate and participate in their movement. Therefore, it allows us to align personal embodiment in projections of collectively anticipated embodiment. Grace is a relational phenomenon that is activated according to the degree to which individuals or communities collectively sympathise with it. The perceived grace of manners and social training is expressed in the subtlety and efficiency of one's 
ability to successfully navigate and prioritise action according to the expectations of a given social milieu. Clumsy dyssynchrony, then, has the unfortunate side effect of generating an unsympathetic collective milieu.

Clumsiness as a tactic of social transformation thus risks being actively distained, pushed aside or quickly made invisible for the very quality of it being out of time, out of place or out of scale. What's worse, the social repercussions of being clumsy would be far more severe for those who already suffer from existing discriminatory paradigms or non-attunement with the status quo, than for those who are implicitly sanctioned to move, act and participate freely. I anticipate that for clumsiness to produce lasting creative and transformative social frictions, it must exploit the awkwardness of non-attunement and irresolution, while simultaneously generating social sympathies (or producing new forms of synchronicity). Clumsiness must be as attuned to developing the parameters of its context and embodiment as dancers are to the coordinated movements of the tango, or as potters are to the plastic weight of spinning clay or as scientists are to the scales and properties of measurement.

I contend that research-creation is an important relational stance from which to activate and sustain clumsy emergence as a creative force. Unlike victims of clumsy non-attunement or those who suffer from and internalise the disciplinary social repercussions of not socially fitting in, research-creation actively develops irresolution, incongruence and discontinuity. Moreover, these disruptive characteristics are not a means to an end, but actually sustain emergent thought, movement and perception. ${ }^{46}$ The clumsiness that is developed through the affective friction, awkwardness and irresolution in creative material and media milieu has the effect of bothering attention so that it remains open to emergent affective and expressive motivation.

We now see how developing sensitivity for emergence in the flux of affective body-forming in attentive clumsiness might extend to developing more plastic and dynamic bordering processes in social and collective contexts. When the embodied, disciplinary sensitivities of social manners and distinctions are unfixed from rigid, habitual delineations, they can emerge as a dynamic topography for creative negotiation. Put otherwise, creative clumsiness initiates a process of shifting, plasticising and modulating emotional investment in exclusionary social behaviour 
by proposing processual, open irresolution and suspended anticipation. The discipline and manners that simultaneously inform material scripts, affective embodiment and affective impulses to exclusionary social behaviour would stand to be redistributed and transformed in the emergent perception of creative negotiation. Therefore, clumsiness could be an effective, systematic technique in research-creation that resonates with the materiality and social dynamics of everyday, affectively charged experience.

Choreographer Simone Forti shows us one example of how methodical and deliberate clumsiness-or the clash of material, formal, reflexive and theoretical registers-activate emergent embodiment via the openness of its own process. ${ }^{47}$ Forti improvises with the surface and dimension of a small table by leaning on it, rolling under it and caressing the subtle taper of its legs. This tactile and physical relation with the table becomes a force of contingent, mobile stability as she proceeds to verbally describe her immediate physical sensations, details about her personal life, her thinking processes and her concern for various injustices around the world. We watch Forti's spry, elderly body dance limberly with the small table and wonder at the strength of her bones compared to the rigidity of the table. We notice the material specificity of her body and the table in high relief. Her physical proximity, her liveness, oscillates between social, personal, linguistic, material, physical and narrative registers. When Forti laments social injustice, the realisation of the limitation of her current physical agency directs us to the paradoxes of reconciling tactile and embodied material immediacy with more general social concerns and representations. Forti can trace the taper of the table leg with her fingers but she cannot physically redistribute the wealth of the world to end poverty. Forti's table choreography leaves many important social questions unanswered. But the social and ethical problems that Forti raises within the expressive embodiment of the performance milieu leaves open a propositional suggestion that resides in the sensory flux of embodiment itself. We are left with the affective impulse to collectively inhabit dynamic, empathetic and sympathetic openness in the ways that we physically, perceptively and affectively inhabit the everyday. 


\section{-CONCLUSION}

The experience of habit often escapes textual description, despite its long history as a subject of theoretical and sociological discussion. At the same time, the very complexity with which we inhabit experience opens infinite entry points for developing techniques to modulate attention, sensation and embodiment. What is particularly important about research-creation as a technique of agentive embodiment is that it sustains perceptive emergence via the dynamism or affective flux in process. Put otherwise, the tension between multiple, disparate registers and qualities of experience form a research ecology that persistently develops in emergent scope and complexity.

Manning explicitly advocates working from multiple perspectives in researchcreation to maintain radical openness in creative research systems. In Creative Propositions for Thought in Motion, she expounds propositions like 'Edit from Within!', 'Value, don't Evaluate!', 'Make Multiple Sense!', 'Speculate!', 'Create with Concepts!', 'Make the Relation Felt!', 'Engage Relations of Tension!', 'Create Degrees of Intimacy!', 'Forget what you Feel!', 'Transvaluate!'.48 In processes that are governed by the potential in their very multiplicity, existing expectations, categories and locations are continually destabilised and renegotiated. A multiple research framework thus extends the agentive potential and immanence of inhabiting the world across disparate vectors. ${ }^{49}$

Similarly, Bruno Latour emphasises the emergent potential of inclusive creative process, or 'compositionist' methods that integrate textual, conceptual and sensory experiential registers. Latour states: 'To capture all creative agencies, compositionists have to compose ... [continuity] slowly and progressively ... from discontinuous pieces.'50 Once again we see that the very process of struggling to articulate, translate and relay experience across registers of meaning, experience and emergent sensation becomes an opportunity for creative embodiment. The advantages involved in engaging disparate sources in research-creation thus extend beyond individual concerns. The plural and dynamic, non-linearity of creative embodiment creates the context or means for collective participation in worldcreation. Creative openness towards diversity, incongruence, irresolution and nonattunement in social contexts potentiates methods for inhabiting more persistent and deliberate forms of collective agentive embodiment. Therefore, the clumsy 
embodiment of research-creation proposes a format for collective willing that is messy and uncoordinated but sustains the transformative potential of embodied emergence. The radicalism of this idea lies in the perceptive and affective subjectivity of social bodies. Therefore, the 'clumsy' embodiment of researchcreation proposes a format for collective willing that is messy and unruly but sustains transformative potential in its emergence and openness across multiple vectors. The radicalism of this idea lies in the potential of the emergent flux of subjective experience in the doing of everyday processes, which disturbs categorical separations between individual and collective bodies. Therefore, the creative tending to the flux of emergent experience means developing techniques and processes for actively inhabiting plastic emergence across existing boundaries of social distinction. As we have seen, the milieu of our immediate experience with everyday materialities is then a crucial tactic for initiating such processes.

Nicole De Brabandere is a doctoral researcher in research-creation at the Zurich University of the Arts, Switzerland and the University of Arts, Linz, Austria. De Brabandere's research focuses on developing expressive techniques for modulating everyday habits and tendencies in a variety of media and material milieu. De Brabandere regularly presents her work in workshops, performances, exhibitions and conferences internationally. <www.nicoledebrabandere.com>

\section{-NOTES}

1 Elaine Scarry, The Body in Pain: The Making and Unmaking of the World, Oxford University Press, New York, 1985, pp. 255, 285. Gilbert Simondon makes a similar observation about the perceptive projection of the body into hand tools, referring to them as 'instruments of perception'. Gilbert Simondon, Du mode d'existence des objets techniques, Édition augmentée. Aubier, Paris, 1989, p. 114 (author's translation).

2 Ibid., pp. 285-6

3 Ibid., p. 285.

${ }^{4}$ Robin Bernstein, 'Dances with Things: Material Culture and the Performance of Race', in Social Text, vol. 101, vol. 27, no. 4, 2007, p. 70.

5 Ibid., p. 68.

${ }^{6}$ Bruno Latour similarly explains that when a substance instantiates 'a redistribution and reallocation of action ... [it] is transformed from an object into a thing, or ... a matter of fact to a matter of concerns'. Bruno Latour, 'Networks, Societies, Spheres: Reflections of an Actor-network Theorist', International Seminar on Network Theory: Network Multidimensionality in the Digital Age, 2010, Bruno Latour,<http://www.bruno-latour.fr/article>, p. 5. 
7 William James, 'A World of Pure Experience', 1904, Classics in the History of Psychology,

<http://psychclassics.yorku.ca/James/experience.htm>.

8 David Ellison, 'Automata for the People: Machine Noise and attention', Cultural Studies Review, vol. 18, no. 3, 2012, p. 136-7, <http://epress.lib.uts.edu.au/journals/index.php/csrj/article/view/2863>.

9 Erin Manning, 'Dance of Attention', Inflexions, no. 6., <http://www.senselab.ca/inflexions/n6_manning.html>

10 Henri Bergson, Time and Free Will: An Essay on the Immediate Data of Consciousness, trans. F.L. Pogson, George Allen and Unwin, London, 1910. p. 27. Available on Internet Archive at:

$<$ https://archive.org/details/timeandfreewilla00berguoft>.

11 Brian Massumi, 'The Thinking-Feeling of What Happens: A Semblance of Conversation', in

Inflexions-How is Research Creation?, no. 1, 2008, p. 5,

<http://www.senselab.ca/inflexions/n1_massumihtml.html>.

12 Ibid., p. 6.

13 Brian Massumi, Parables for the Virtual: Movement, Affect, Sensation, Duke University Press, Durham and London, 2002, pp. 3-4.

14 Ibid., p. 6.

15 Erin Manning, Relationscapes: Art, Movement, Philosophy, Cambridge, MIT Press, 2009, p. 19.

16 Erin Manning, Politics of Touch: Sense, Movement Sovereignty, University of Minnesota Press,

Minnesota, 2007, p. 6.

17 Unfortunately, most of Stuart's performances are not available online. An example of an early version of Stuart's movement language can be seen at <http://vimeo.com/81482778>.

18 Gabriele Brandstetter describes the affective bodying of Stewart's choreographies as deconstructive inversions of the body that fundamentally 'break' with 'logical' embodiment processes (rather than an elastic bodying process): 'broken at the core, they reflect the inversions of processes that do not follow a simple developmental logic, but rather deal with gaps, breaks and absences in their dynamic',

Gabriele Brandstetter, 'Pose-Posa-Posing-Between Image and Movement' in Fashion Body Cult, eds

Elke Bippus and Dorthea Mink Arnoldsche Art Publishers, Stuttgart, 2007, pp. 264.

19 Bergson, p. 34.

20 Tim Bayne, 'The Sense of Agency' in The Senses: Classic and Contemporary Philosophical Perspectives, ed. Fiona Macpherson, Oxford University Press, New York, 2011, p. 307.

21 John Dewey, Human Nature and Conduct: An Introduction to Social Psychology, Henry Holt and

Company, New York, 1922, Available as a Project Gutenburg E-Book,

<http://www.gutenberg.org/files/41386/41386-h/41386-h.htm>, pp. 41-2.

22 Ibid., p. 31.

${ }^{23}$ Gilles Deleuze, Différence et Répétition, Presses Universitaires de France, Paris, 1968, p. 107 (author's translation).

24 Ibid.

25 Ellison, p. 136.

26 Bergson, pp. 26-7.

27 Ronald Melzack and Patrick D. Wall, 'Pain Mechanisms: A New Theory', Science, vol. 150, no. 3699, 1965, pp. 971-9.

28 65, pp. 971-9.

29 Massumi, Parables for the Virtual, p. 210.

${ }^{30}$ Philipp Reicherts, Antje B.M. Gerdes, Paul Pauli and Wieser, J. Matthias, 'On the Mutual Effects of Pain and Emotion: Facial Pain Expressions Enhance Pain Perception and Vice Versa are Perceived as More Arousing when Feeling Pain', Journal of the International Association for the Study of Pain, vol. 154, no. 6, 2013, pp. 793-800. 
31 Justin 0. Schmidt, 'Hymenoptera Venoms: Striving toward the Ultimate Defense against Vertebrates', in Insect Defenses: Adaptive Mechanisms and Strategies of Prey and Predators, eds D. L. Evans and J. O. Schmidt, State University of New York Press, Albany, 1990, pp. 387-419, quoted from Shelley Batts, 'Schmidt Pain Index: Which Sting Hurts the Worst?' in Retrospectacle: A Neuroscience Blog, Science Blogs, 16 May 2007, <http://scienceblogs.com/retrospectacle/2007/05/16/schmidt-pain-indexwhich-sting/>.

32 Ibid.

33 This tendency among 'tactile drawing' participants could be explained by the paradox of body consciousness in movement as both occupying a specific position and being constituted in a relational milieu: 'body consciousness implies a field of consciousness simultaneously constituted as a point of consciousness', José Gil, 'The Dancer's Body', in A Shock to Thought: Expression After Deleuze and Guattari, ed. Brian Massumi, Routledge, London and New York, 2002, p. 122.

34 Deleuze's description of difference pertains to the tactile drawing experience: 'Difference is a matter of degree when on a scale that describes it; it is a difference of nature when it is recovered from this scale by its quality. Between differences of degree and of nature there are degrees of difference that are intensive.' Deleuze, Différence et Répétition, p. 309 (author's translation).

35 Thomas Lamarre, 'Diagram, Inscription, Sensation', in A Shock to Thought: Expression after Deleuze and Guattari, ed. Brian Massumi, Routledge, London and New York, 2002, pp. 162.

36 Andrew Murphy, 'Deleuze, Guattari, and Neuroscience', in Deleuze, Science and the Force of the Virtual, ed. Peter Gaffney University of Minnesota Press, Minneapolis, 2010, pp. 277-99.

39 Murphy, p. 281.

37 Ibid., p. 281.

38 John Dewey, Human Nature and Conduct: An Introduction to Social Psychology, Henry Holt and Company, New York, 1922. p. 71. Dewey insists that the mechanisms of embodied and accumulated habits are indispensible for all life but he distinguishes between those of the artist and those of the technician, suggesting that the artist practises a skill towards greater complexity and flexibility, while in the work of the technician there is a 'prevalence of dead habits deflects life into mere élan', 39 Bergson, pp. 17-18.

40 Giaco Schiesser, 'Working on and With Eigensinn', trans. Tom Morrison, 2005, Distributed Creativity, $<$ http://distributedcreativity.org/>

41 Sara Ahmed, The Cultural Politics of Emotion, Routledge, New York, 2004, p. 91.

42 Ibid.

43 Sara Ahmed, 'Things that get Stuck: On Will, Walls and Willfulness', keynote presentation, ASCA International Conference and Workshop, Amsterdam, 18 April 2013.

44 Bergson, p. 13.

45 Ibid.

46 Gilbert Simondon suggests that the methodological structure of aesthetic activity creates and preserves worlds of meaning through its own re-articulation: 'aesthetic activity preserves the structure of its own re-articulation by constructing a world in which it can continue to exist'. Du mode d'existence des objets techniques, Édition augmentée, Aubier, Paris, 1989, p. 184 (author's translation).

47 Simone Forti, Otis Presentation, 2010, YouTube,

<http://www.youtube.com/watch?v=29VCs5TBY5I>.

48 Erin Manning, 'Creative Propositions for Thought in Motion', Inflections-How is Research Creation?, no. 1, 2008, <http://www.inflexions.org/n1_manninghtml.html>.

${ }^{49}$ Rob Nixon similarly suggests that generating multiple discontinuities from linear conceptual frameworks has the effect of 'thickening time'. It is within the multiplicity and immediacy of temporal 'thickness' that new potential movements to collective consciousness become felt, activating a more deliberate and thorough response to a range of social crises. Rob Nixon, 'Slow Violence and the 
Environmentalism of the Poor: An Interview with Rob Nixon', with Ashley Dawson (interviewer), Social Text Interviews, 2011 <http://www.socialtextjournal.org/blog/2011/08/slow-violence-and-theenvironmentalism-of-the-poor-an-interview-with-rob-nixon.php>.

50 Bruno Latour, 'An Attempt at a Compositionist Manifesto' New Literary History, vol. 41, 2010

<http://www.bruno-latour.fr/sites/default/files/120-NLH-GB.pdf>, p. 484.

\section{-BIBLIOGRAPHY}

Ahmed, S., 'Things that get Stuck: On Will, Walls and Willfulness', keynote presentation, ASCA International Conference and Workshop, Amsterdam, 18 April 2013.

Ahmed, S., The Cultural Politics of Emotion, Routledge, New York, 2004.

Alaimo, S. and S. Hekman (eds), Material Feminisms, Indiana University Press, Bloomington and Indianapolis, 2008.

Barad, K., 'Posthumanist Performativity: Toward and Understanding of How Matter Comes to Matter', in Material Feminisms, eds Stacey Alaimo and Susan Hekman Indiana University Press, Bloomington and Indianapolis, 2008.

Batts, S., 'Schmidt Pain Index: Which Sting Hurts the Worst?' in Retrospectacle: A Neuroscience Blog, Science Blogs, 16 May 2007, http://scienceblogs.com/retrospectacle/2007/05/16/schmidtpain-index-which-sting/.

Bayne, T., 'The Sense of Agency' in The Senses: Classic and Contemporary Philisophical Perspectives, ed. Fiona Macpherson, Oxford University Press, New York, 2011.

Bergson, H., Time and Free Will: An Essay on the Immediate Data of Consciousness, trans. F.L. Pogson, George Allen and Unwin, London, 1910.

Bernstein, R., 'Dances with Things: Material Culture and the Performance of Race', in Social Text, vol. 101, vol. 27, no. 4, 2007.

Deleuze, G., Différence et Répétition, Presses Universitaires de France, Paris, 1968.

Dewey, J., Human Nature and Conduct: An Introduction to Social Psychology, Henry Holt and Company, New York, 1922.

Dewey, J., Human Nature and Conduct: An Introduction to Social Psychology, Henry Holt and Company, New York, 1922.

Ellison, D., 'Automata for the People: Machine Noise and Attention', in Cultural Studies Review, vol. 18, no. 3, 2012, http://epress.lib.uts.edu.au/journals/index.php/csrj/article/view/2863.

Evans, D. L. and J. O. Schmidt (eds), Insect Defenses: Adaptive Mechanisms and Strategies of Prey and Predators, State University of New York Press, Albany, 1990.

Forti, S., Otis Presentation, 2010, YouTube, http://www.youtube.com/watch?v=29VCs5TBY5I.

Gaffney, O. (ed.), Deleuze, Science and the Force of the Virtual, ed. University of Minnesota Press, Minneapolis, 2010.

Gil, J., 'The Dancer's Body', in A Shock to Thought: Expression After Deleuze and Guattari, ed. Brian Massumi, Routledge, London and New York, 2002. 
James, W., 'A World of Pure Experience', 1904, Classics in the History of Psychology,

<http://psychclassics.yorku.ca/James/experience.htm>.

Lamarre, T., 'Diagram, Inscription, Sensation', in A Shock to Thought: Expression after Deleuze and Guattari, ed. Brian Massumi, Routledge, London and New York, 2002.

Latour, 'An Attempt at a Compositionist Manifesto' New Literary History, vol. 41, 2010 <http://www.bruno-latour.fr/sites/default/files/120-NLH-GB.pdf>.

Latour, B., 'Networks, Societies, Spheres: Reflections of an Actor-network Theorist', International Seminar on Network Theory: Network Multidimensionality in the Digital Age, 2010, Bruno Latour, http://www.bruno-latour.fr/article.

Macpherson, F. (ed.), The Senses: Classic and Contemporary Philosophical Perspectives, Oxford University Press, New York, 2011.

Manning, E., 'Creative Propositions for Thought in Motion', Inflections-How is Research Creation?, no. 1, 2008, <http://www.inflexions.org/n1_manninghtml.html>.

Manning, E., 'Dance of Attention', in Inflexions-Arakawa and Gins special issue of Inflexions, no. 6. <http://www.senselab.ca/inflexions/n6_manning.html>.

Manning, E., Politics of Touch: Sense, Movement Sovereignty, University of Minnesota Press, Minnesota, 2007. Brandstetter, G., 'Pose-Posa-Posing_Between Image and Movement' in Fashion Body Cult, eds Elke Bippus and Dorthea Mink, Arnoldsche Art Publishers, Stuttgart, 2007.

Manning, E., Relationscapes: Art, Movement, Philosophy, Cambridge, MIT Press, 2009. doi: http://dx.doi.org/10.7551/mitpress/9780262134903.001.0001

Massumi, B. (ed.), A Shock to Thought: Expression after Deleuze and Guattari, Routledge, London and New York, 2002.

Massumi, B., 'The Thinking-Feeling of What Happens: A Semblance of Conversation', in Inflexions-How is Research Creation?, no. 1, 2008, p. 5, <http://www.senselab.ca/inflexions/n1_massumihtml.html>

Massumi, B., Parables for the Virtual: Movement, Affect, Sensation, Duke University Press, Durham and London, 2002. doi: http://dx.doi.org/10.1215/9780822383574

Melzack, R. and P. D. Wall, 'Pain Mechanisms: A New Theory', Science, vol. 150, no. 3699, 1965. doi: http://dx.doi.org/10.1126/science.150.3699.971

Murphy, A., 'Deleuze, Guattari, and Neuroscience', in Deleuze, Science and the Force of the Virtual, ed. Peter Gaffney University of Minnesota Press, Minneapolis, 2010.

Nixon, R., 'Slow Violence and the Environmentalism of the Poor: An Interview with Rob Nixon', with Ashley Dawson (interviewer), Social Text Interviews, 2011, <http://www.socialtextjournal.org/blog/2011/08/slow-violence-and-theenvironmentalism-of-the-poor-an-interview-with-rob-nixon.php>.

Reicherts, P., A. B. M. Gerdes, P. Pauli and W. J. Matthias, 'On the Mutual Effects of Pain and Emotion: Facial Pain Expressions Enhance Pain Perception and Vice Versa are Perceived as More 
Arousing when Feeling Pain', Journal of the International Association for the Study of Pain, vol. 154, no. 6, 2013.

Scarry, E., The Body in Pain: The Making and Unmaking of the World, Oxford University Press, New York, 1985.

Schiesser, G., 'Working on and With Eigensinn', trans. Tom Morrison, Distributed Creativity, 2005, http://distributedcreativity.org/.

Schmidt, J. O., 'Hymenoptera Venoms: Striving toward the Ultimate Defense against Vertebrates', in Insect Defenses: Adaptive Mechanisms and Strategies of Prey and Predators, eds D. L. Evans and J. O. Schmidt, State University of New York Press, Albany, 1990.

Simondon, G., Du mode d'existence des objets techniques, Édition augmentée. Aubier, Paris, 1989. 